\title{
Bone and Soft Tissue Changes after Two-Jaw Surgery in Cleft Patients
}

\author{
Yung Sang Yun ${ }^{1}$, Ki Il Uhm ${ }^{1}$, Jee Nam Kim ${ }^{1}$, Dong Hyeok Shin ${ }^{1}$, Hyun Gon Choi ${ }^{1}$, \\ Soon Heum Kim², Cheol Keun Kim², Dong In Jo ${ }^{2}$ \\ ${ }^{1}$ Department of Plastic and Reconstructive Surgery, Konkuk University Medical Center, Konkuk University School of Medicine, Seoul; \\ ${ }^{2}$ Department of Plastic and Reconstructive Surgery, Konkuk University School of Medicine, Chungju, Korea
}

Background Orthognathic surgery is required in 25\% to 35\% of patients with a cleft lip and palate, for whom functional recovery and aesthetic improvement after surgery are important. The aim of this study was to examine maxillary and mandibular changes, along with concomitant soft tissue changes, in cleft patients who underwent LeFort I osteotomy and sagittal split ramus osteotomy (two-jaw surgery).

Methods Twenty-eight cleft patients who underwent two-jaw surgery between August 2008 and November 2013 were included. Cephalometric analysis was conducted before and after surgery. Preoperative and postoperative measurements of the bone and soft tissue were compared.

Results The mean horizontal advancement of the maxilla (point A) was $6.12 \mathrm{~mm}$, while that of the mandible (point B) was $-5.19 \mathrm{~mm}$. The mean point A-nasion-point $B$ angle was $-4.1^{\circ}$ before surgery, and increased to $2.5^{\circ}$ after surgery. The mean nasolabial angle was $72.7^{\circ}$ before surgery, and increased to $88.7^{\circ}$ after surgery. The mean minimal distance between Rickett's E-line and the upper lip was $6.52 \mathrm{~mm}$ before surgery and $1.81 \mathrm{~mm}$ after surgery. The ratio of soft tissue change to bone change was 0.55 between point $A$ and point $A^{\prime}$ and 0.93 between point $B$ and point B'.

Conclusions Patients with cleft lip and palate who underwent two-jaw surgery showed optimal soft tissue changes. The position of the soft tissue (point A') was shifted by a distance equal to $55 \%$ of the change in the maxillary bone. Therefore, bone surgery without soft tissue correction can achieve good aesthetic results.

Keywords LeFort osteotomy / Sagittal split ramus osteotomy / Cleft lip and palate / Orthognathic surgery
Correspondence: Ki II Uhm Department of Plastic and Reconstructive Surgery, Konkuk University Medical Center, Konkuk University School of Medicine, 120-1 Neungdong-ro, Gwangjin-gu, Seoul 143-729, Korea

Tel: $+82-2-2030-7380$

Fax: +82-2-2030-5249

E-mail:20110112@kuh.ac.kr

Received: 26 Dec $2014 \bullet$ Revised: 1 Apr 2015 - Accepted: 22 Apr 2015

pISSN: 2234-6163 • elSSN: 2234-6171 • http://dx.doi.org/10.5999/aps.2015.42.4.419 • Arch Plast Surg 2015;42:419-423

No potential conflict of interest relevant to this article was reported.

\section{INTRODUCTION}

Orthognathic surgery is required in $25 \%-30 \%$ of patients with a cleft lip and palate due to serious malocclusion, disturbance of the growth of the jaws, and/or discrepancies in the development of maxillomandibular alignment $[1,2]$. The purpose of orthog- nathic surgery is not only to recover functions such as mastication and pronunciation, but also to improve facial aesthetics [3]. Therefore, the ability to predict postoperative changes in bone and soft tissue is crucial. This study was conducted in order to contribute to the accurate evaluation of such changes.

Previous studies have only focused on upper jaw or soft tissue 
alterations in cleft patients who underwent LeFort I osteotomy. Since no studies, to the best of our knowledge, have been conducted on cleft patients who have undergone both LeFort I osteotomy and sagittal split ramus osteotomy (two-jaw surgery), or have investigated soft tissue alterations caused by changes to the maxilla and mandible, this study aimed to examine such changes.

\section{METHODS}

\section{Patients}

The subjects were 26 patients with cleft lip and palate who underwent two-jaw surgery performed by a senior surgeon between August 2008 and November 2013. Eighteen of the subjects were males and eight were females, and the subject were 18-38 years of age (mean, 19.3 years). Unilateral cleft lip and palate was present in 21 patients, while the remaining five patients had bilateral cleft lip and palate. The mean follow-up period was 6.8 months (range, 6-14 months).

Surgery was performed after wrist radiographs confirmed that the growth plate was closed. Cephalometric analysis was conducted before surgery and after the patients underwent both LeFort I osteotomy and sagittal split ramus osteotomy.

\section{Cephalometric method and statistical analysis}

The cephalogram obtained before surgery was referred to as T1; and the cephalogram obtained six months after surgery was referred to as T2. Tracing and cephalometric analysis of the lateral $\mathrm{T} 1$ and $\mathrm{T} 2$ cephalograms were conducted. The Frankfort horizontal line was designated as the $\mathrm{X}$-axis, and the line passing through the porion, perpendicular to the $\mathrm{X}$-axis, was designated as the Y-axis. Cephalometric anatomical landmarks and reference lines were selected (Fig. 1).
Skeletal changes in the maxilla and mandible were determined by analyzing the sella-nasion-point A (SNA) angle and sella-nasion-point $\mathrm{B}$ (SNB) angle on $\mathrm{T} 1$ and $\mathrm{T} 2$, in which point $\mathrm{A}$ (subspinale) was on the maxilla, and point $B$ (supramentale) was on the mandible. Changes from $\mathrm{T} 1$ to $\mathrm{T} 2$ in the point A-nasion-point $\mathrm{B}$ (ANB) angle and the distance from point $\mathrm{A}$ and point $\mathrm{B}$ to the $\mathrm{X}$-axis and the $\mathrm{Y}$-axis were also evaluated. Regarding soft tissue changes, the following parameters were measured on $\mathrm{T} 1$ and $\mathrm{T} 2$ in order to measure horizontal changes in the facial profile: the distance from point $A^{\prime}$ and point $B^{\prime}$ to the Y-axis, the nasolabial angle, and the shortest distance between Rickett's E-line and the upper lip. In order to measure vertical changes in the facial profile, the distance from point $\mathrm{A}^{\prime}$ and point $\mathrm{B}^{\prime}$ to the $\mathrm{X}$-axis, and the ratio of upper lip length to lower lip length were measured on $\mathrm{T} 1$ and $\mathrm{T} 2$.

All tracing and cephalometric analysis were conducted twice by two doctors who did not participate in the surgery. The Wilcoxon signed-rank test was used for statistical analysis, with the level of significance set at a P-value of $<0.05$.

\section{RESULTS}

Table 1 presents skeletal changes in the maxilla and mandible. The mean horizontal advancement of the maxilla (Y-A) was $6.12 \mathrm{~mm}(\mathrm{P}=0.022)$, while the mean vertical lengthening (XA) was $1.33 \mathrm{~mm}(\mathrm{P}=0.572)$. The mean horizontal setback of the mandible (Y-B) was $-5.19 \mathrm{~mm}(\mathrm{P}=0.048)$, while the mean vertical lengthening $(\mathrm{X}-\mathrm{B})$ was $0.98 \mathrm{~mm}(\mathrm{P}=0.492)$.

The mean SNA angle showed a marked increase of $3.1^{\circ}$, from $78.4^{\circ}$ before surgery to $81.5^{\circ}$ after surgery $(\mathrm{P}=0.07)$. The mean SNB angle showed a significant decrease of $3.7^{\circ}$, from $82.7^{\circ}$ before surgery to $79^{\circ}$ after surgery $(\mathrm{P}=0.015)$. The mean ANB

\section{Fig. 1. Cephalometric landmarks and reference lines}

S, sella: the estimated center of the bony contour of the preoperative sella turcica; $N_{\text {, }}$ nasion: the most anterior point of the frontonasal suture; $A$, subspinale, the point at the deepest midline concavity on the maxilla below the anterior nasal spine; Prn, pronasale: the most prominent point on the apex of the nose; $A^{\prime}$, soft-tissue subspinale: the point of greatest concavity in the midline of the upper lip; $B$, supramentale: the point at the deepest midline concavity of the mandibular symphysis; B', soft-tissue supramentale: the point of the greatest concavity in the midline of the lower lip; Eline, a line drawn from the most prominent point on the apex of the nose (Prn) to the soft tissue pogonion $\left(\mathrm{Pg}^{\prime}\right) ; \mathrm{Cm}-\mathrm{Sn}-\mathrm{Ls}$, nasolabial angle; $\mathrm{LS}$, labrale superius: the most prominent point on the prolabium of the upper lip; $\mathrm{Cm}$, columella: the most anterior point of the columella; Sn, subnasale: the deepest point in the nasolabial curvature; $\mathrm{FH}$, FH plane: the line connecting the porion and orbitale; Stms, stomion superius: the lowermost point of the upper lip; Stmi, stomion inferius: the uppermost point of the lower lip; Me', soft-tissue menton, the most inferior point on the chin; Po, porion: the most superior point on the border of external auditory meatus; $G$, soft-tissue glabella: the most anterior point on the soft-tissue glabella; Or, orbitale: the lowest point on the inferior margin of the orbit; Li, labrale inferius: the most prominent point on the prolabium of the lower lip.

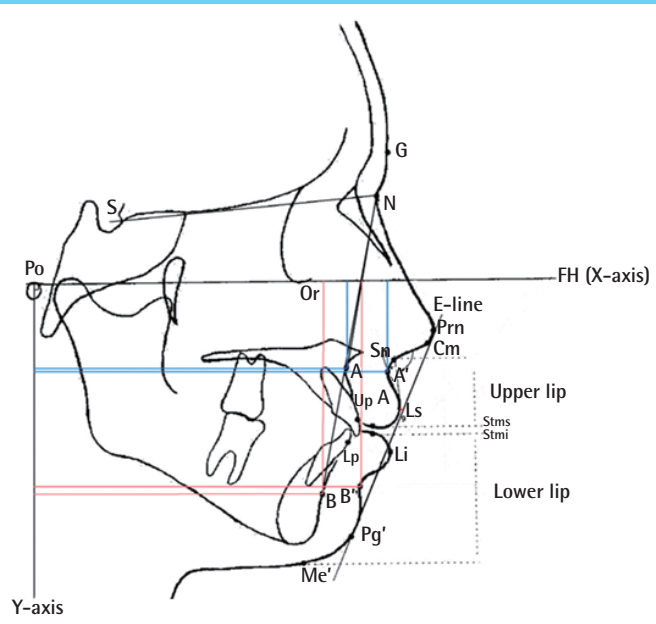

Y-axis 
Table 1. Skeletal changes of the maxilla and mandible

\begin{tabular}{|c|c|c|c|c|c|c|c|}
\hline \multirow{2}{*}{ Landmark } & \multicolumn{2}{|c|}{ T1 (preoperative) } & \multicolumn{2}{|c|}{ T2 (6 mo postoperatively) } & \multicolumn{2}{|c|}{ Skeletal change } & \multirow{2}{*}{ P-value } \\
\hline & Mean & SD & Mean & SD & $\mathrm{T} 2-\mathrm{T} 1$ & SD & \\
\hline$X$ axis- $A(m m)$ & 44.53 & 4.77 & 45.86 & 3.97 & 1.33 & 4.96 & 0.572 \\
\hline Y axis-A (mm) & 97.01 & 1.08 & 103.13 & 3.44 & 6.12 & 3.44 & $0.022^{a)}$ \\
\hline$X$ axis-B $(\mathrm{mm})$ & 91.07 & 7.78 & 92.05 & 7.61 & 0.98 & 6.36 & 0.492 \\
\hline Y axis-B (mm) & 93.86 & 13.88 & 88.67 & 13.91 & -5.19 & 7.18 & $0.048^{\mathrm{a})}$ \\
\hline $\operatorname{SNA}\left(\left(^{\circ}\right)\right.$ & 78.40 & 5.30 & 81.50 & 3.84 & 3.10 & 4.07 & 0.070 \\
\hline SNB $\left(0^{\circ}\right)$ & 82.70 & 3.50 & 79.00 & 4.11 & -3.70 & 3.37 & $0.015^{\mathrm{a})}$ \\
\hline ANB $\left(^{\circ}\right)$ & -4.10 & 4.31 & 2.50 & 3.14 & 6.60 & 3.60 & $0.002^{\mathrm{a})}$ \\
\hline
\end{tabular}

$T$ 1, preoperative stage (within a month before operation); $T 2$, postoperative stage (six months after orthognathic surgery); SD, standard deviation; $X$ axis- $A$, distance from the A point to the $X$-axis $(\mathrm{mm}) ; Y$ axis-A, distance from the A point to the $Y$-axis $(\mathrm{mm}) ; X$ axis-B, distance from the $B$ point to the $X$-axis (mm); $Y$ axis-B, distance from the $B$ point to the $Y$-axis (mm); SNA, angle of the N-S to N-A line; SNB, angle of the N-S to N-B line; ANB, angle of the N-A to N-B line.

a) $\mathrm{P}$-value $<0.05$

\section{Table 2. Soft tissue changes of the maxilla and mandible}

\begin{tabular}{|c|c|c|c|c|c|c|c|}
\hline \multirow{2}{*}{ Landmark } & \multicolumn{2}{|c|}{ T1 (preoperative) } & \multicolumn{2}{|c|}{ T2 (6 mo postoperatively) } & \multicolumn{2}{|c|}{ Surgical change } & \multirow{2}{*}{ P-value } \\
\hline & Mean & SD & Mean & SD & $\mathrm{T} 2-\mathrm{T} 1$ & SD & \\
\hline $\mathrm{X}$ axis-A' (mm) & 42.18 & 3.82 & 42.29 & 4.39 & 0.11 & 2.96 & 0.826 \\
\hline Y axis-A' (mm) & 108.81 & 11.27 & 112.19 & 11.15 & 3.38 & 6.23 & 0.105 \\
\hline$X$ axis-B' (mm) & 88.16 & 7.88 & 89.03 & 9.36 & 0.87 & 7.96 & 0.845 \\
\hline Y axis-B' (mm) & 108.30 & 15.97 & 103.49 & 16.17 & -4.81 & 8.11 & 0.105 \\
\hline Nasolabial angle $\left({ }^{\circ}\right)$ & 72.70 & 5.30 & 88.70 & 3.84 & 16.00 & 9.35 & $0.002^{\mathrm{a})}$ \\
\hline E-line $(m m)$ & 6.52 & 3.44 & 1.81 & 3.48 & -4.71 & 3.02 & $0.002^{\mathrm{a})}$ \\
\hline X axis-Prn (mm) & 28.90 & 2.94 & 29.52 & 3.29 & 0.62 & 2.21 & 0.546 \\
\hline Y axis-Prn (mm) & 128.5 & 12.01 & 128.99 & 10.58 & 0.44 & 7.06 & 0.492 \\
\hline Upper lip length (mm) & 24.53 & 4.93 & 27.30 & 4.15 & 2.77 & 4.95 & 0.099 \\
\hline Lower lip length (mm) & 54.27 & 5.50 & 53.44 & 5.41 & -0.83 & 2.22 & 0.414 \\
\hline Lower lip/upper lip ratio & 2.29 & 0.49 & 1.99 & 0.29 & -0.31 & 0.49 & $0.050^{\mathrm{a})}$ \\
\hline soft tissue $A-A^{\prime}$ (mm) & 15.37 & 4.02 & 16.15 & 3.20 & 0.78 & 2.51 & 0.432 \\
\hline soft tissue B-B' (mm) & 15.92 & 2.90 & 16.49 & 3.66 & 0.58 & 2.76 & 0.789 \\
\hline
\end{tabular}

$T 1$, preoperative stage (within a month before operation); T2, postoperative stage (six months after orthognathic surgery); SD, standard deviation; $X$ axis- $A^{\prime}$, distance from the $A^{\prime}$ point to the $X$-axis $(\mathrm{mm}) ; Y$ axis-A', distance from the A' point to the $Y$-axis $(\mathrm{mm}) ; X$ axis-B', distance from the $B^{\prime}$ point to the $X$-axis $(\mathrm{mm}) ; Y$ axis- $B^{\prime}$, distance from the $B^{\prime}$ point to the $Y$-axis $(\mathrm{mm})$; nasolabial angle, angle of the columella tangent line to the upper lip tangent line; $E$-line, the shortest distance from the upper lip to $E$-line; $X$ axisPrn, the distance from Prn to X-axis (mm); Y axis-Prn, distance from Prn to the Y-axis (mm); Upper lip length, distance from Sn to Stms (mm); Lower lip length, distance from Stmi to $M e^{\prime}(\mathrm{mm})$; soft tissue A-A', distance from A to $A^{\prime}(\mathrm{mm})$; soft tissue B-B', distance from B to $B^{\prime}(\mathrm{mm})$.

a) -value $<0.05$.

angle increased significantly by $6.6^{\circ}$, from $-4.1^{\circ}$ before surgery to $2.5^{\circ}$ after surgery $(\mathrm{P}=0.002)$.

Table 2 shows soft tissue changes in the maxilla and mandible. The mean horizontal advancement of point $\mathrm{A}^{\prime}$ (Y-A') was 3.38 $\mathrm{mm}$, while the mean vertical lengthening $\left(X-\mathrm{A}^{\prime}\right)$ was $0.11 \mathrm{~mm}$. The mean horizontal movement of point $\mathrm{B}^{\prime}$ (Y-B') was -4.81 $\mathrm{mm}$, while the mean vertical lengthening $\left(\mathrm{X}-\mathrm{B}^{\prime}\right)$ was $0.87 \mathrm{~mm}$. None of these changes were statistically significant.

The mean nasolabial angle showed a significant increase of $16^{\circ}$, from $72.7^{\circ}$ before surgery to $88.7^{\circ}$ after surgery $(\mathrm{P}=0.002)$. The minimal distance between Rickett's E-line and the upper lip showed a significant of $4.71 \mathrm{~mm}$, from $6.52 \mathrm{~mm}$ before surgery to $1.81 \mathrm{~mm}$ after surgery $(\mathrm{P}=0.002)$. The mean horizontal advancement of the pronasale (Y-Prn) was $0.44 \mathrm{~mm}$, while the mean vertical lengthening (X-Prn) was $0.62 \mathrm{~mm}$, neither of which were statistically significant.

The mean upper lip length increased by $2.77 \mathrm{~mm}$, from 24.53 $\mathrm{mm}$ before surgery to $27.30 \mathrm{~mm}$ after surgery, whereas the mean lower lip length decreased by $0.83 \mathrm{~mm}$, from $54.27 \mathrm{~mm}$ before surgery to $53.44 \mathrm{~mm}$ after surgery, which were not significant changes. The ratio of the lower lip to the upper lip decreased from 2.29 before surgery to 1.99 after surgery $(P=0.05)$, demonstrating a significant change.

The soft tissue thickness of the upper lip, as determined by the A-A $\mathrm{A}^{\prime}$ distance, showed a mean increase of $0.78 \mathrm{~mm}$, from 15.37 $\mathrm{mm}$ before surgery to $16.15 \mathrm{~mm}$ after surgery. The mean soft tissue thickness of the lower lip, as determined by the B-B' distance, increased by $0.58 \mathrm{~mm}$, from $15.92 \mathrm{~mm}$ before surgery to 
Table 3. Ratio of soft tissue movement to bone movement

\begin{tabular}{|lccc|}
\hline Ratio & $\begin{array}{c}\text { Soft tissue } \\
\text { change }(\mathbf{m m})\end{array}$ & $\begin{array}{c}\text { Bone change } \\
(\mathbf{m m})\end{array}$ & Ratio \\
\hline$Y$ axis-A' $/ Y$ axis-A & 3.38 & 6.12 & 0.55 \\
$X$ axis-A' $/ X$ axis-A & 0.11 & 1.33 & 0.08 \\
$Y$ axis-B' $/$ axis-B & -4.81 & -5.19 & 0.93 \\
$X$ axis-B' $/ X$ axis-B & 0.87 & 0.98 & 0.89 \\
\hline
\end{tabular}

$Y$ axis- $A^{\prime}$, distance from the $A^{\prime}$ point to the $Y$-axis $(\mathrm{mm}) ; Y$ axis-A, distance from the $A$ point to the $Y$-axis $(\mathrm{mm}) ; X$ axis- $A^{\prime}$, distance from the $A^{\prime}$ point to the $X$-axis $(\mathrm{mm}) ; X$ axis-A, distance from the $A$ point to the $X$-axis $(\mathrm{mm}) ; Y$ axis- $B^{\prime}$, distance from the $B^{\prime}$ point to the $Y$-axis $(\mathrm{mm}) ; Y$ axis- $B$, distance from the $B$ point to the $Y$-axis $(\mathrm{mm}) ; X$ axis- $B^{\prime}$, distance from the $B^{\prime}$ point to the $X$-axis $(\mathrm{mm}) ; X$ axis- $B$, distance from the $B$ point to the $X$-axis $(\mathrm{mm})$.

$16.49 \mathrm{~mm}$ after surgery. These changes were not statistically significant.

Table 3 presents the ratio of soft tissue change to bone change. For the maxilla and upper lip soft tissue, this ratio was 0.55 regarding mean horizontal advancement, while it was 0.08 for mean vertical lengthening. For the mandible and lower lip soft tissue, the ratio of soft tissue change to bone change was 0.93 regarding mean horizontal retrusion was 0.93 , while it was 0.89 for mean vertical lengthening.

\section{Case 1}

A 20-year-old man with cleft lip and palate had a history of primary cheiloplasty three months after birth, palatoplasty at one year of age, secondary cheiloplasty at seven years of age, and secondary cheiloplasty at eight years of age. The patient underwent two-jaw surgery to correct a class III malocclusion that caused problems with mastication and aesthetic dissatisfaction. A preoperative photo and cephalogram of the patient at 20 years of age and a postoperative photo and cephalogram taken six months after surgery are shown in Fig. 2.

The horizontal advancement of the maxilla (Y-A) was $4.6 \mathrm{~mm}$, the vertical lengthening (X-A) was $3.8 \mathrm{~mm}$. the horizontal setback of the mandible (Y-B) was $-8 \mathrm{~mm}$, and the vertical lengthening (X-B) was $1.3 \mathrm{~mm}$. The SNA angle increased by $7^{\circ}$, from $75^{\circ}$ before surgery to $82^{\circ}$ after surgery. The SNB angle decreased by $1^{\circ}$, from $83^{\circ}$ before surgery to $82^{\circ}$ after surgery. The ANB angle increased by $8^{\circ}$, from $-6^{\circ}$ before surgery to $2^{\circ}$ after surgery. The horizontal advancement of point $\mathrm{A}^{\prime}\left(\mathrm{Y}^{-\mathrm{A}^{\prime}}\right)$ was $5.7 \mathrm{~mm}$, and its vertical lengthening $\left(\mathrm{X}-\mathrm{A}^{\prime}\right)$ was $1.9 \mathrm{~mm}$. The horizontal movement of point $\mathrm{B}^{\prime}\left(\mathrm{Y}-\mathrm{B}^{\prime}\right)$ was $-7.9 \mathrm{~mm}$, and its vertical lengthening $\left(\mathrm{X}-\mathrm{B}^{\prime}\right)$ was $0.8 \mathrm{~mm}$. The nasolabial angle increased by $35^{\circ}$, from $65^{\circ}$ before surgery to $100^{\circ}$ after surgery. The minimal distance between Rickett's E-line and the upper lip decreased by $5.9 \mathrm{~mm}$, from $6.8 \mathrm{~mm}$ before surgery to $0.9 \mathrm{~mm}$ after surgery. Upper lip length increased by $2.2 \mathrm{~mm}$, from $27 \mathrm{~mm}$ before sur-

\section{Fig. 2. Case 1}

(A) preoperative photography, (B) preoperative cephalogram, (C) postoperative photography at six-month follow-up, (D) postoperative cephalogram at six-month follow-up.
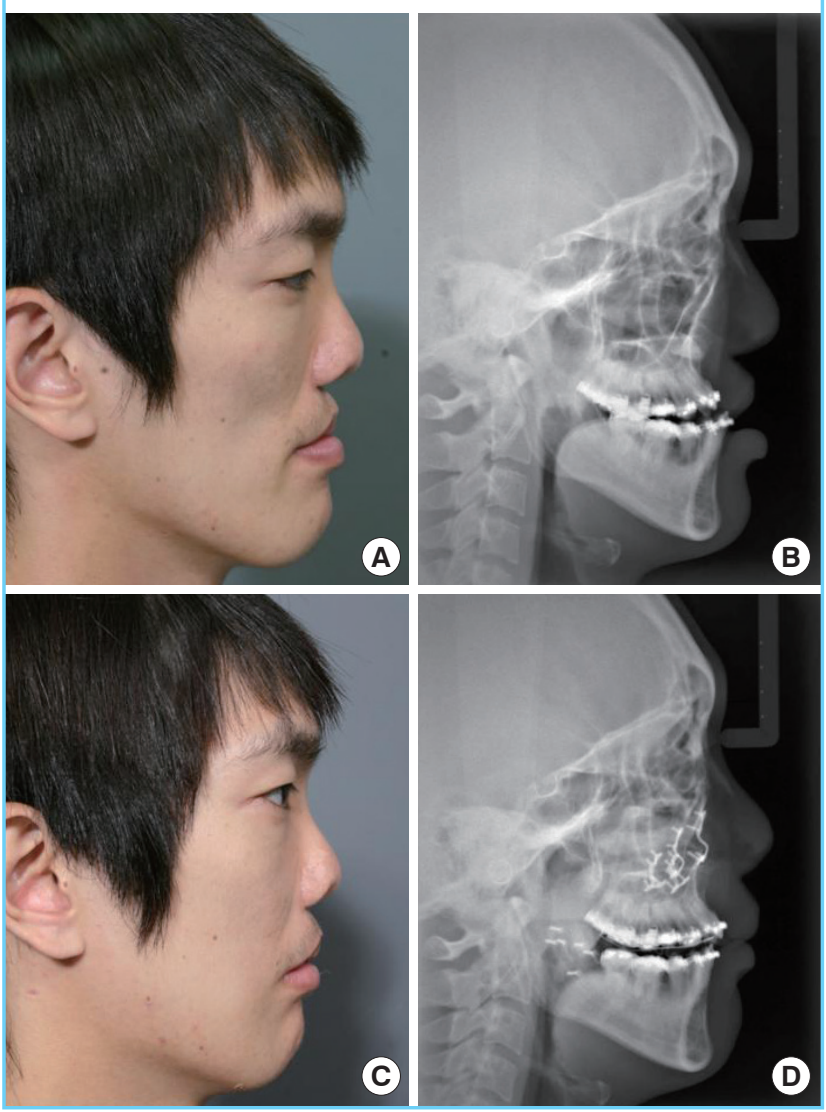

gery to $29.2 \mathrm{~mm}$ after surgery, and lower lip length increased by $0.5 \mathrm{~mm}$, from $60.8 \mathrm{~mm}$ before surgery to $61.3 \mathrm{~mm}$ after surgery. The ratio of the lower lip to upper lip decreased from 2.25 before surgery to 2.09 after surgery.

In conclusion, the ANB angle and nasolabial angle increased, the minimal distance between Rickett's E-line and the upper lip decreased, and the ratio of the lower lip to upper lip converged to an ideal number, resulting in an aesthetically improved facial profile.

\section{DISCUSSION}

Even if patients undergo surgical correction for cleft lip and palate at a young age, $25 \%$ to $30 \%$ require orthognathic surgery due to the development of severe midface retrusion [1]. In this study, changes to the bone and soft tissue of the maxilla and mandible in patients who underwent both LeFort I osteotomy and sagittal split ramus osteotomy (two-jaw surgery) were examined and compared with the ideal aesthetic standard.

The horizontal advancement of the maxillary soft tissue was 
$55 \%$ of the horizontal advancement of the maxilla itself. The maxillary soft tissue underwent $8 \%$ of the vertical lengthening observed in the maxilla itself. The horizontal retrusion of the mandibular soft tissue was $93 \%$ of the corresponding value observed in the mandible. The mandibular soft tissue underwent vertical lengthening to an extent corresponding to $89 \%$ of that observed in the mandible itself.

The soft tissue thickness of the upper lip after two-jaw surgery was predicted to decrease due to bone advancement; however, contrary to this prediction, a mean increase of $0.78 \mathrm{~mm}$ was observed. The soft tissue thickness of the lower lip was predicted to increase due to bone retrusion, and, as predicted, a mean increase of $0.58 \mathrm{~mm}$ was observed, although this change was not statistically significant.

Soft tissue changes of the maxilla were small in comparison with bone changes; however, the soft tissue changes caused by bone changes of the mandible were substantial. The reason for this discrepancy is that the soft tissue around the maxilla is more closely interconnected to tissue in the nose, cheek, and the surrounding area than is the soft tissue around the mandible. Furthermore, soft tissue around the maxilla generally has much more scar tissue due to previous palatoplasties [4]. Consequently, additional procedures, such as paranasal augmentation, may be helpful in order to ensure that the midface has the desired shape. For the lower face, in contrast, additional augmentation is not always required, and sagittal split ramus osteotomy alone can induce bone changes that lead to the desired shape.

The SNA angle is an index showing the location of the maxilla in relation to the anterior cranial base; a normal SNA angle is $82^{\circ} \pm 2^{\circ}[5]$. In this study, the mean SNA angles before and after surgery were $78.4^{\circ}$ and $81.5^{\circ}$, respectively; this does not reflect a statistically significant change, although the mean angle after surgery was within the normal range. The SNB angle is an index showing the location of the mandible in relation to the anterior cranial base; a normal SNB angle is $80^{\circ} \pm 2^{\circ}$ [5]. In our study, the mean SNB angle before surgery was $82.7^{\circ}$, decreasing to $79^{\circ}$ after surgery, which is within the normal range $(\mathrm{P}=0.015)$. The ANB angle represents the relationship between the maxilla and mandible; a normal ANB angle is $2^{\circ}-4^{\circ}[5]$. The mean ANB angle in this study was $-4.1^{\circ}$ before surgery, and was within the normal range after the surgery $\left(2.5^{\circ}, \mathrm{P}=0.002\right)$.

The normal nasolabial angle is $102^{\circ} \pm 2^{\circ}[5]$. Prior to surgery, the mean nasolabial angle was $72.7^{\circ}$, but after surgery, it was closer to the normal range $\left(88.7^{\circ}, \mathrm{P}=0.002\right)$. The normal minimal distance between Rickett's E-line and the upper lip is $4 \mathrm{~mm}$ or less [5]. Before surgery, the value for this parameter was 6.52 $\mathrm{mm}$, but it was within the normal range after surgery $(1.81 \mathrm{~mm}$, $\mathrm{P}=0.002$ ). The most aesthetically pleasing ratio of upper to low- er lip length is 1:2 [6]. After surgery, this parameter became close to ideal $(1.99, \mathrm{P}=0.05)$.

Solely as a result of changes to the maxilla and mandible in twojaw surgery, all values, including the nasolabial angle, the minimal distance between Rickett's E-line and the upper lip, and the ratio of upper to lower lip lengths, which reflect soft tissue changes, became ideal. Thus, bone surgery without soft tissue correction is capable of achieving good aesthetic results. For cleft patients, two-jaw surgery not only induces bone changes, but also significantly affects soft tissues, thereby greatly improving facial aesthetics.

Most of the patients were able to achieve a desirable outcome after two-jaw surgery without additional aesthetic surgery, but additional correction may be needed in some patients. The results reported in this article help to accurately predict soft tissue changes following changes in the maxilla and mandible after two-jaw surgery, thus potentially facilitating the prediction of which patients may need additional aesthetic surgery.

No relapse was observed during the follow-up period.

One limitation of this study is the small number of patients. Future studies should have a larger number of patients, as well as a longer postoperative follow-up period, in order to study the possibility of relapse, which, if existent, should be examined for its severity and the exact degree of changes involved therein.

\section{REFERENCES}

1. DeLuke DM, Marchand A, Robles EC, et al. Facial growth and the need for orthognathic surgery after cleft palate repair: literature review and report of 28 cases. J Oral Maxillofac Surg 1997;55:694-7.

2. Ross RB. Treatment variables affecting facial growth in complete unilateral cleft lip and palate. Cleft Palate J 1987;24:577.

3. Chang IH, Lee YJ, Park YG. A comparative study of soft tissue changes with mandibular one jaw surgery and double jaw surgery in Class III malocclusion. Korean J Orthod 2006; 36:63-73.

4. Sumi Y, Hata KI, Sawaki Y, et al. Clinical application of cultured oral epithelium for palatal wounds after palatoplasty: a preliminary report. Oral Dis 1999;5:307-12.

5. Dua G, Navin Kumar A, Roy ID, et al. Maxillary distraction osteogenesis in cleft lip and palate cases with midface hypoplasia using rigid external distractor: an alternative technique. J Craniofac Surg 2014;25:746-51.

6. Lee TS, Kim HY, Kim TH, et al. Contouring of the lower face by a novel method of narrowing and lengthening genioplasty. Plast Reconstr Surg 2014;133:274e-282e. 